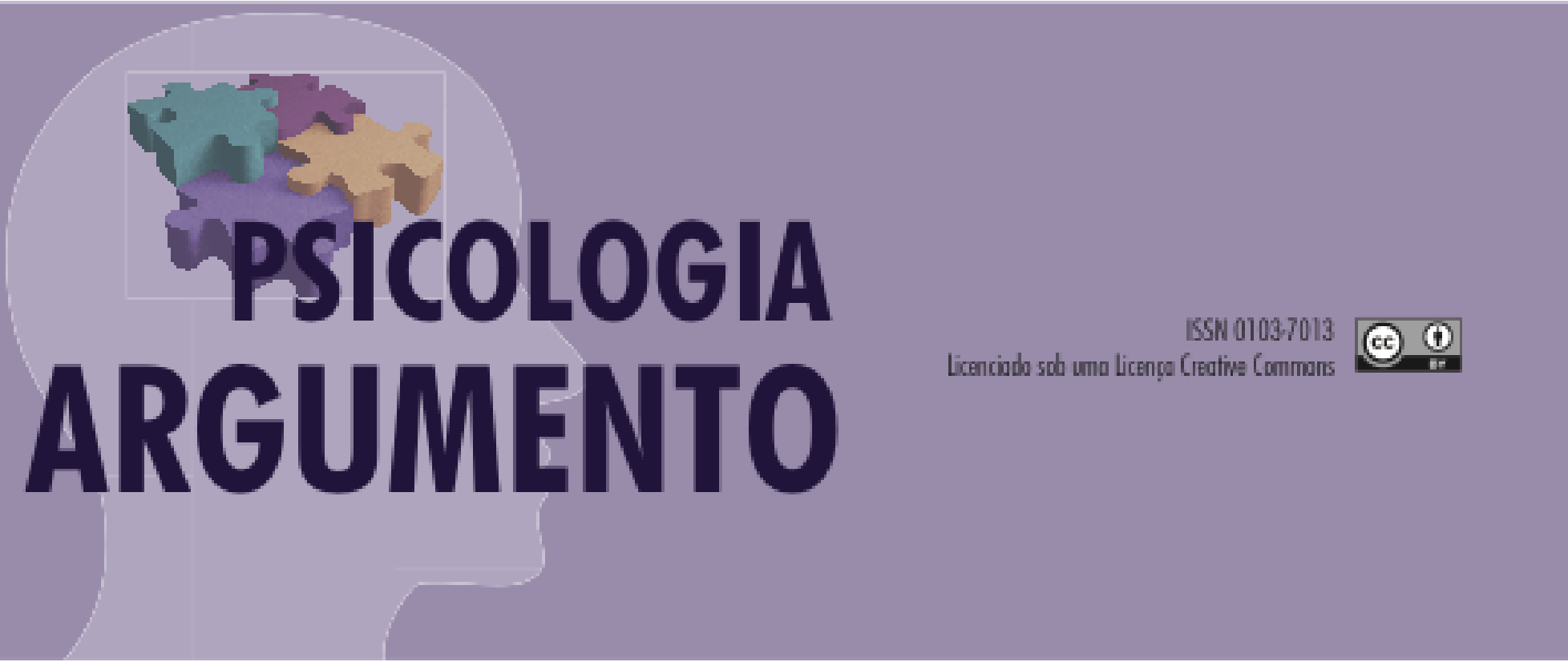

doi: 10.7213/psicol.argum.33.080.A007

\title{
Habilidades sociais e resiliência em futuros professores
}

\author{
Social skills and resilience in future teachers
}

Rosana Angst Pasqualotto [a], Suzane Schmidlin Löhr [b]

[a] Professora da PUCPR, e-mail: roangst@gmail.com

[b] Professora da UFPR, e-mail: lohr@superig.com.br

\section{Resumo}

Ser professor nos dias atuais exige muito do profissional. Se ele não consegue lidar com as demandas diárias de sua profissão, passa a vivenciar altos níveis de estresse que podem vir a impedi-lo de trabalhar, por levar a enfermidades físicas e psicológicas. Manejar os desafios diários se faz de diferentes maneiras para cada pessoa e envolve aspectos como resiliência e habilidades sociais. Pensando em tais variáveis, foi realizado um estudo com 86 acadêmicos de último ano de licenciaturas, avaliando o repertório de habilidades sociais e o grau de resiliência dos mesmos, relacionando com variáveis sociodemográficas e histórico profissional. Na grande maioria, os respondentes apresentaram bom repertório de habilidades sociais e de resiliência. A relação entre as duas variáveis merece ser melhor estudada futuramente, mas os achados apontam para a estimulação do desenvolvimento de habilidades sociais em futuros professores como alternativa para a emissão de comportamentos resilientes.

Palavras-chave: Alunos de licenciaturas, Habilidades Sociais, Resiliência. 


\begin{abstract}
Being a teacher nowadays demands a lot of the professional. If he/she is not able to deal with the daily job demands of his/her profession, he/she will have high levels of stress that can stop him/her to work, and can lead them physical and psychological diseases. Each person deals with the daily challenges differently, and it involves aspects as resilience and social skills. Thinking about those variables, it was made a study with 86 undergraduate students, evaluating their social skills and resilience repertoire and related with social demographical variables and professional history. Most of the participants presented a good social skills and resilience repertoire. The relationship between those two variables deserves to be better studied in the future, but these findings points out that the stimulation of the social skills development in teachers to-be is an alternative to increase resilience repertoire.
\end{abstract}

Keywords: Teaching degree, Social Skills, Resilience.

\title{
Introdução
}

Ser professor nos dias atuais exige muito do profissional. Os docentes precisam ter habilidades para lidar com situações delicadas, como violência em sala de aula, utilização adequada de novas tecnologias, compreender diferentes composições familiares e sua interferência no ambiente escolar, lidar adequadamente com a diversidade de valores, dentre outros (Soares \& Mello, 2010; Del Prette \& Del Prette, 2011; Leite \& Löhr, 2012; Pretsch, Flunger \& Schmitt; 2012). A atuação em sala de aula pode ser gratificante e produtiva, mas também é capaz de gerar desconforto e conflito. Para que as dificuldades sejam minimizadas e a realização com o desempenho no trabalho se destaque, é preciso que o profissional que optar pela docência tenha manejo de turma para trabalhar os conteúdos previstos de forma adequada, além de sensibilidade para lidar com assuntos/situações delicadas que venham a ocorrer em sala de aula.

O aluno passa a maior parte do seu dia na escola, e é lá que estabelece diferentes relações com colegas de sala, equipe pedagógica e professores. O modelo e estímulo dado pelo professor para a promoção de interações produtivas tanto com o professor como com os colegas pode contribuir para a formação integral do educando e também tornar o clima no âmbito da escola mais harmônico e saudável. Arroyo (2009) e Soares et al., (2009) defendem que o papel do educador na escola vai além da transmissão de conhecimento, sendo ele também responsável pela promoção do desenvolvimento socioemocional de seu aluno. Para Fajardo, Minayo e Moreira $(2010,2013)$ a escola é um dos ambientes capazes de auxiliar na superação das adversidades. O professor, em sala de aula, pode auxiliar o aluno não apenas a aprender conteúdos de forma efetiva, mas também ser um adulto como referência para a resolução de conflitos e troca de experiências. Quando os professores são vistos como uma referência para seus alunos, a relação entre eles é fortalecida, e o processo ensino-aprendizagem se mostra mais efetivo (Camargo, 2004).

Porém é importante lembrar que quando um professor não consegue lidar com as demandas diárias de sua profissão pode desenvolver enfermidades físicas e psicológicas decorrentes do estresse que enfrenta em sala de aula e vir a comprometer seu trabalho enquanto educador. Atualmente fala-se que os professores estão passando pelo mal-estar docente, decorrente de um nível elevado de demandas a cumprir, pouco tempo para fazêlas, pressão para transmitir conteúdos e garantir o aprendizado de seus alunos (Barros \& 
Louzada, 2007). Fajardo, Minayo e Moreira (2013) lembram que a forma de lidar com as diversas questões que hoje compõem o fazer do educador pode afetar o seu desempenho em sala de aula e vir a comprometer a sua saúde mental.

Deparar-se com dificuldades faz parte do processo em qualquer profissão. Se as mesmas forem vistas como desafios, quando superados, possibilitam o aprendizado para encarar as problemáticas relacionadas ao exercício profissional. Em tais circunstâncias o professor estará aproveitando inclusive os momentos difíceis para o seu aprimoramento. Se os desafios fazem parte do exercício profissional, se muitas das demandas hoje relatadas pelos professores estão associadas a aspectos culturais da atualidade, por que alguns professores conseguem lidar com elas enquanto outros sucumbem às exigências do meio? Entender a diversidade de respostas às demandas do ambiente por parte dos professores remete à análise do conceito de resiliência.

A resiliência é definida como a capacidade de passar por situações adversas e superálas, de forma que a experiência vivenciada gere crescimento pessoal (Masten, 2014). Está relacionada com as diferentes respostas diante uma situação de risco (Rutter, 2007), e não pode ser considerada uma característica herdada, e sim fruto da interação dinâmica da pessoa com o ambiente. Não é apropriado defini-la como um traço de personalidade, pois cada pessoa age diferentemente em determinada situação, e pode não apresentar atitudes resilientes em todos os momentos de sua vida (Rutter, 2007; Poletto \& Koller, 2008; Masten, 2014).

Poletto e Koller (2008) afirmam haver fatores de risco e de proteção, os quais tem potencial, respectivamente, para inibir ou promover resiliência. Os fatores de risco são eventos aversivos que ocorrem durante o desenvolvimento, e quando presentes aumentam a probabilidade de a pessoa apresentar problemas físicos, sociais e emocionais. Ao depararse com os embates ligados ao exercício profissional, professores com baixo nível de resiliência ou desistem do cargo, ou apenas vão à escola para receber seu salário e fazer o mínimo para tal, o que gera grande desgaste emocional. Se o professor não conseguir trabalhar com os conflitos no ambiente escolar de forma adequada, ensinar torna-se mais difícil, e em consequência, a aprendizagem de seus alunos pode ser influenciada negativamente (Camargo, 2004). Embora os fatores de risco precisem ser observados, a atenção do presente artigo recai nos chamados fatores de proteção, já que eles podem alterar ou melhorar as respostas de cada pessoa diante de uma situação de desadaptação ou risco.

Ao deparar-se com uma situação aversiva, se o indivíduo contar com fatores de proteção que o auxiliem, pode passar pelo problema de uma forma mais amena, com menores traumas emocionais e maior adaptação. Assis, Pesce e Avanci (2006) classificam os fatores de proteção em individual, familiar e social. Os fatores individuais estão relacionados às estratégias que cada pessoa desenvolve, em sua história de vida, para lidar com as adversidades. A família, seja nuclear ou estendida, pode vir a auxiliar o indivíduo quando se depara com um contexto adverso, passando a constituir um forte pilar para o encaminhamento que se fizer necessário. Contextos e instituições também podem auxiliar o indivíduo no momento que precise de apoio, tecendo uma rede de proteção. São considerados ambientes sociais promotores de resiliência: as escolas, igrejas, grupos de apoio, psicoterapia, ambiente de trabalho. Tais contextos têm em comum o fato de serem espaços promotores de oportunidades para que a pessoa seja exposta a situações envolvendo desafios e também por disponibilizar redes de apoio. Aprender a lidar de forma produtiva com situações de risco é um fator de proteção que a auxilia no cumprimento das tarefas e na busca de pontos de mudança (turning points) (Rutter, 2007). Um professor que lida diariamente com situações aversivas em seu ambiente laboral, que seria um fator de risco, caso tenha, por exemplo, o apoio da equipe pedagógica da escola, esse suporte pode ser consi- 
derado um ponto de mudança para melhorar seu manejo com adversidades, tendo maior probabilidade de emitir comportamentos resilientes. Um professor que apresenta características resilientes pode ter maiores chances de permanecer exercendo suas atividades docentes.

Outro conceito, tão central para o exercício profissional do professor quanto a resiliência e que interage com o primeiro, é o denominado de habilidades sociais. Para lidar com os problemas relacionados ao ambiente escolar, além de manejar de forma adequada as adversidades, é preciso traquejo para relacionar-se socialmente, fazendo uma boa leitura do contexto. As relações interpessoais são beneficiadas quando as pessoas envolvidas em cada episódio social têm condições de analisar e compreender com clareza a situação presente, verificar os aspectos que a controlam, para então poder agir de forma segura atendendo às especificidades do momento, se respeitando e respeitando ao outro. A leitura do ambiente é uma das chamadas habilidades sociais.

As habilidades sociais são definidas por Gresham (2009) como comportamentos aceitáveis aprendidos socialmente, que permitem à pessoa interagir efetivamente com outros, evitando ou fugindo de comportamentos não aceitáveis que possam resultar em interações negativas.Se uma pessoa tem bom nível de habilidades sociais e exercita-as, provavelmente terá construído uma rede social maior, que pode, em momentos difíceis, servir-lhe de apoio. Esta é uma área de pesquisa que merece maior investigação, tendo alguns resultados preliminares apresentados por Loureiro e Sanches (2006) e Del Prette e Del Prette (2006). Del Prette e Del Prette (2006) afirmam que as habilidades sociais podem ser consideradas um fator de proteção para a promoção da resiliência, pois se a pessoa é capaz de falar o que sente em situações de conflito e dificuldade, tem a maior probabilidade de resolvê-las efetivamente.

A formação acadêmica deve capacitar o professor didaticamente para exercer a sua função, mas ao entrar em sala de aula, os futuros professores podem não estar seguros para ministrar aulas e resolver conflitos. Loureiro e Sanches (2006) salientam que ter competência para lidar produtivamente com as tarefas tanto evolutivas como de resolução de problemas é considerado central para que ocorra o processo de resiliência. Arroyo (2010) acrescenta que o desafio de saber lidar com a adversidade e ter atitudes resilientes deve ser estimulado em professores e alunos. Desde meados do século XX autores como Alberti e Emmons (1978) alertavam que atividades visando ao desenvolvimento de habilidades sociais relacionadas à prática profissional deveriam fazer parte das propostas curriculares do terceiro grau, pois assim os docentes aprenderiam de maneira formal como lidar com situações adversas no contexto pessoal e profissional. Em artigo mais atual, Del Prette e Del Prette (2007) defendem o mesmo encaminhamento, que é apresentado também por eles e por outros estudiosos no relato de pesquisas (Del Prette \& Del Prette, 2008; Lopes, 2010; Gatti, 2010).

Dada a importância para o educador, tanto da resiliência, quanto das habilidades sociais, será descrito um estudo em que tais variáveis foram levantadas junto a um grupo de formandos em licenciaturas em uma universidade pública do Estado do Paraná. O objetivo do presente trabalho foi buscar relações entre o repertório de habilidades sociais, resiliência, variáveis sociodemográficas e histórico profissional dos participantes do estudo.

\section{Método}

Participaram da presente pesquisa 86 acadêmicos que cursavam o último ano de licenciaturas e de Pedagogia de uma universidade pública do Estado do Paraná. Na universidade alvo do estudo, os cursos são ofertados por Setor, que no período de coleta de dados se 
dividiam em: Setor de Ciências Humanas, Letras e Artes, no qual foram aplicados questionários nos cursos de Artes Visuais, Ciências Sociais e Música; Setor de Ciências Biológicas e da Saúde sendo participante do estudo, deste Setor, o curso de Ciências Biológicas; Setor de Ciências Exatas do qual participaram do estudo os cursos de Física e Química; e Setor de Educação, cujos respondentes eram do curso de Pedagogia, único curso que está alocado no Setor.

A amostra foi selecionada por conveniência, sendo que todos os coordenadores de cursos envolvendo as licenciaturas foram contatados e informados do estudo. Do total de 14 cursos que oferecem a modalidade de licenciatura na instituição em que foi realizada a pesquisa, sete autorizaram a consulta aos acadêmicos dos cursos sob sua coordenação, sendo que não foi recebido autorização dos outros sete coordenadores. Os questionários foram aplicados a todos os alunos que, após os esclarecimentos sobre o estudo, manifestaram interesse em participar. $\mathrm{O}$ número de alunos que respondeu à pesquisa corresponde a $40 \%$ do total de alunos matriculados nas licenciaturas dos cursos inseridos no estudo.

Os participantes responderam a: 1) Inventário de Habilidades Sociais IHS-DelPrette (Del Prette \& Del Prette, 2001); 2) Escala de Resiliência (ER) (Pesce et al., 2005); 3) Questionário de comportamentos resilientes (QCR): elaborado pelas autoras da presente pesquisa para complementar dados comportamentais não explicitados na Escala de Resiliência; e 4) Questionário sociodemográfico: composto por questões referentes à história de aprendizagem e de experiência dos respondentes (se tinham filhos, se já trabalharam como educadores ou como se sentiram no desempenho da função entre outros).

O projeto foi submetido ao Comitê de Ética em Pesquisa (CEP) e aprovado, recebendo o parecer número 107.809. Após a aprovação da pesquisa no CEP, foi verificada a grade horária dos cursos, procurando identificar quando grande parte da turma compareceria à universidade. Foi então feito contato com o professor que estaria desenvolvendo atividade naquele horário para os alunos, para que autorizasse a utilização de uma parte de sua aula para a apresentação do estudo aos acadêmicos. Posterior à autorização do professor da disciplina, foi exposto o projeto da pesquisa aos acadêmicos, os quais foram convidados a participar do mesmo. Antecedendo à aplicação dos questionários e após esclarecimento oral sobre o estudo, foi entregue o Termo de Consentimento Livre e Esclarecido. Os que concordaram em participar responderam aos instrumentos no ambiente de sala de aula. A consigna foi padronizada e os participantes responderam então de forma individual ao questionário sociodemográfico, Escala de Resiliência, Questionário de Comportamentos Resilientes e Inventário de Habilidades Sociais, em um período aproximado de 20 minutos.

\section{Resultados e discussão}

Houve a predominância de participantes do sexo feminino $(n=65 ; 75,6 \%)$, o que reflete uma realidade brasileira, pois maior número de mulheres nos cursos de licenciatura é verificado também em outros estudos (Vedovato \& Monteiro, 2008; Gatti, 2010). A idade média dos respondentes foi de $24,95+6,51$ anos. A maioria é solteira $(n=70 ; 81,4 \%)$ e 8 respondentes possuem filhos $(9,3 \%)$, tendo uma média de 1,75 filhos. Doze participantes do estudo (14\%) afirmaram já ter cursado outra graduação e 55 (64\%) afirmaram trabalhar. A carga horária média de trabalho é de $29,38+11,75$ horas semanais. Vinte e sete (39\%) relatam trabalhar atualmente como professor, e $22(25,6 \%)$ já trabalharam como professor em algum momento da vida, o que leva ao total de $49(61,3 \%)$ respondentes engajados, no presente ou no passado, com a docência.

Dos 49 respondentes que afirmaram já ter trabalhado como professor, $44(89,8 \%)$ gostam de ser professor, e $40(81,6 \%)$ se sentem realizados trabalhando como professor. Mesmo alguns participantes que relataram gostar de ser professor $(n=33 ; 67,3 \%)$, mencionam ter tido em algum momento o desejo de desistir da profissão. É importante ressaltar que tais pensamentos ocorreram apenas esporadicamente aos respondentes $(\mathrm{n}=27 ; 55,1 \%)$. Afirmações desta natureza corroboram o estresse a que profissionais da educação são submetidos, o qual pode fazer com que mesmo pessoas que amam o que fazem, sintam em alguns momentos desejo de desistir da profissão (Arroyo, 2010). 
A maioria dos participantes da pesquisa que relata já ter trabalhado na educação sente que frequentemente tem ou tinha controle de turma $(n=34 ; 69,4 \%)$.Considerando tratar-se de pessoas que estão finalizando cursos de graduação na modalidade licenciatura, que fizeram a opção, portanto, de provavelmente vir a integrar os quadros docentes das escolas, ao afirmarem que nas experiências prévias sentiram ter controle de turma, apontam para uma visão bastante promissora no que diz respeito ao futuro das relações professor aluno. É importante lembrar, no entanto, que com o passar do tempo esse profissional pode se sentir frustrado com as diversas situações conflitantes do ambiente escolar, o que pode, em longo prazo, comprometer sua saúde física e mental, como apontam alguns estudos (Benevides-Pereira, 2002).

$\mathrm{O}$ escore de habilidades sociais dos respondentes foi medida com instrumento específico para tal fim, o IHS (IHS-DEL-PRETTE). A média do escore total encontrado foi 97,04, o que é considerado um bom repertório. Nos cinco fatores avaliados pelo IHSDEL-PRETTE (F1 - Enfrentamento/autoafirmação com risco; F2 - Autoafirmação do afeto positivo; F3 - Conversação e desenvoltura social; F4 - Autoexposição a desconhecidos e situações novas; F5 - Autocontrole da agressividade) a média dos respondentes apontou para escores indicativos de bom repertório. Gomes e Soares (2013) enfatizam que um aluno ao entrar em um curso de graduação enfrenta muitas dificuldades acadêmicas e pessoais, e que se consegue chegar ao fim desde, aprendeu de forma sistemática ou assistemática a resolver situações conflitantes relacionadas ao ambiente acadêmico. $\mathrm{O}$ bom resultado encontrado na presente amostra pode indicar que essas são pessoas com boa habilidade social pessoal, aumentando as chances de que venham a ser modelos efetivos para o desenvolvimento de tais habilidades em seus alunos. Infelizmente não foi avaliado o repertório dos respondentes para estimular o desenvolvimento de habilidades sociais em outrem, de forma que não temos como precisar se eles saberão estimular o desenvolvimento de respostas habilidosas socialmente em seus alunos. Os dados a seguir, relativos à probabilidade de emitir respostas habilidosas socialmente no contexto de trabalho, apontam para aspectos não sanados, que precisam ser melhor explorados e trabalhados na formação de professores.

Para verificar se cada respondente fazia uso de habilidades sociais no seu trabalho, nas escolas, foi indagado se conseguiam dizer o que pensavam aos alunos e aos colegas de trabalho. Pouco menos da metade dos respondentes $(44,9 \%)$ acredita dizer o que deveria ser dito aos alunos, sendo que este número cai quase para a metade quando a questão é direcionada aos colegas de trabalho. Apenas 24,49\% afirmaram posicionar-se de forma produtiva em situações envolvendo colegas de trabalho. Leite e Löhr (2012) alertam que há um elevado índice de professores que adoecem em decorrência de situações aversivas que acontecem no ambiente de trabalho, e grande parte destas estão relacionadas a problemas de relacionamento interpessoal. Se o profissional da educação é capaz de dizer o que sente tanto para seus alunos como para seus colegas terá maiores chances de lidar de forma adequada com os conflitos que surgirem no ambiente escolar.

Arroyo (2010) enfatiza que o fazer docente envolve muitas questões problemáticas, entre elas o sentimento de desvalorização, o que pode levar o professor a desistir do seu trabalho. Mas, segundo o mesmo autor, o que faz com que o professor continue seu trabalho, apesar das dificuldades, é a vontade de sempre querer se aperfeiçoar e fazer o melhor, e mesmo que a situação seja difícil, continuar na profissão.

Considerando que muitas das situações descritas como problemáticas no contexto escolar envolvem dificuldades de comunicação, e que nestes casos, bom domínio de habilidades sociais poderia facilitar a solução da questão, professores iniciantes que recebam preparo nesta área, teriam um fator a mais favorecendo sua permanência bem-sucedida no trabalho. Neste sentido, poder-se-ia dizer que bom domínio de habilidades sociais age como fator de proteção nas adversidades, contribuindo para que a pessoa eleve o seu grau de resiliência. É possível que professores cuja história de aprendizagem tenha produzido oportunidades para o desenvolvimento de habilidades sociais, tenham maiores recursos para lidar com os desafios que enfrentam na escola, aumentando a probabilidade de manter-se na profissão. Já que estamos diante de habilidades, as quais, pelo próprio conceito, podem vir a ser desenvolvidas, parece que a sugestão de autores como Del Prette e Del Prette (2008), Lopes (2010), Gatti (2010) e Richardson (2013) de que cursos de graduação 
direcionadas a licenciaturas promovam espaço para o desenvolvimento de habilidades sociais, constituiria uma forma de investir no desenvolvimento de fatores de proteção na resiliência, o que teria reflexos na qualidade da educação ofertada à população.

A média do escore dos respondentes $(132,79)$ na Escala de Resiliência (ER) corresponde ao valor médio apontado em outros estudos realizados com universitários (Pretsch, Flunger \& Schmitt, 2012; Moser, Amorim \& Angst, 2013). A pesquisa envolveu graduandos de licenciaturas que se candidataram a responder aos instrumentos e não uma população com problemas específicos. A correspondência dos resultados do presente estudo com os resultados de outros estudos realizados com universitários em geral e não apenas matriculados em licenciaturas, fortalece os dados, levando gradativamente a uma definição do que seria um nível médio de resiliência. Este parece ser um aspecto importantíssimo, já que os instrumentos para avaliar resiliência disponíveis não definem um valor que seja considerado ponto de corte entre o que seria adequado e a partir do qual estaríamos diante de pessoas com dificuldade quanto à resiliência. É possível que estudos futuros de meta análise tenham elementos para um posicionamento neste sentido.

A comparação por sexo das médias (estatística $t$ do teste $\mathrm{T}$ para amostras independentes e p-valores) dos escores de resiliência (ER e QCR) e o escore total de habilidades sociais (IHS-Del-Prette) não apontou diferenças estatísticas ( $p>0,05)$, concluindo-se, portanto, que o sexo não se constitui em variável digna de nota, ao menos na amostra estudada, no que diz respeito ao escore total de resiliência e de habilidades sociais. Ao realizar a análise independentemente do sexo, foi encontrada uma suave tendência de elevação de ER total à medida que se elevava a classificação de IHS. Este achado pode apontar para correlação entre escores de habilidades sociais e grau de resiliência. Contudo, tais médias ainda assim não apresentaram diferenças significativas $(F 3,82=0,46753$; $p>0,05)$, de forma que novos estudos precisam ser realizados, para então tirar-se conclusões mais consistentes nesta direção.

O Questionário de Comportamentos Resilientes (QCR) foi desenvolvido para o presente estudo e não passou por crivos de análise do instrumento, porém é interessante notar que os resultados de tal instrumento apresentaram correlação com os achados da Escala de Resiliência (ER), um instrumento utilizado em vários estudos sobre resiliência (Moraes \& Carlotto, 2010; Pretsch, Flunger \& Schmitt, 2012; Moser, Amorim \& Angst, 2013). Foi verificada também correlação positiva entre o resultado do QCR com o escore total do IHS-Del-Prette e com os Fatores 3 (conversação e desenvoltura social) e 4 (autoexposição a desconhecidos e situações novas) do IHS. Pode-se conjecturar que ter habilidades sociais, especialmente em conversação e desenvoltura social e facilidade na autoexposição a desconhecidos e situações novas, favorece o lidar com adversidades de forma adequada. Esse é um argumento também apontado por Loureiro e Sanches (2006) e Del Prette e Del Prette (2006), ao afirmarem que para lidar com adversidades de forma adequada é importante desenvolver um repertório de habilidades sociais.

A correlação significativamente negativa entre o Fator 3 do IHS (Conversação e desenvoltura social) e o tempo que atua como professor $(r=-0,31 ; p=0,03)$ verificada no estudo, indica que quanto maior o tempo que a pessoa se dedica à docência, sua capacidade de conversação e de relacionar-se de forma interpessoal parece sofrer embotamento. Este é um dado preocupante, pois pode ser um indício do que é definido como síndrome de burnout (Benevides-Pereira, 2002). O nível de exigência do trabalho como professor é alto e pode causar um esgotamento físico e emocional, alterando, consequentemente, a forma como a pessoa responde aos estímulos presentes no ambiente, levando a comprometimento na saúde mental. Destas análises surgem questões que suscitam novos estudos: um professor com bom nível de habilidades sociais poderia construir uma rede social maior de apoio, a qual teria efeito positivo nos momentos em que a pressão do trabalho pudesse levar ao embotamento afetivo?

Outra correlação negativa observada, foi entre o Fator 2 do IHS-Del-Prette (Autoafirmação na expressão do sentimento positivo) e a carga horária semanal de trabalho ( $\mathrm{r}=$ $0,31 ; \mathrm{p}=0,01)$, indicando que quanto maior é a carga semanal de trabalho, menor é a autoafirmação de afeto positivo. Um professor que tem uma carga de trabalho semanal elevada parece ter menos tempo para expressar sentimentos positivos e reforçadores para seus alunos, pois como provavelmente possui muitas aulas para ministrar, pode não con- 
seguir ter a relação próxima e afetuosa com seus alunos como gostaria de ter. Este também é um dado que acompanha a literatura sobre o desgaste do profissional da educação, que pode provocar um quadro de estresse crônico, culminando na síndrome de burnout (Benevides-Pereira, 2002).

Foi realizada a regressão linear entre variáveis que buscavam responder à pergunta de pesquisa, ou seja, a relação entre habilidades sociais e resiliência. Concluiu-se que apesar de os dados apresentarem uma correlação significativa, uma variável não prediz a outra de forma robusta, sendo necessário encontrar outras variáveis que possam melhor explicar as variáveis da resiliência e das habilidades sociais. Foi então realizada análise multivariada, a qual será mostrada a seguir. Na análise de redundância verificou-se a formação de dois grupos principais, os quais em conjunto apresentaram um padrão de explicabilidade de $95,271 \%$ sobre a variação dos dados das variáveis.

Grupo 1 - agrupado entre os escores negativos. Estas pessoas apresentam valores de ER, QCR e IHS-Del-Prette significativamente menores do que o segundo grupo, e caracterizam-se por parte da amostra ser do curso de Ciências Sociais, Artes Visuais, Física, Música, sendo que em sua maioria são do sexo feminino, solteiros, sem filhos e mais jovens. Grande parte destes alunos não trabalha, e dentre eles, os que já trabalharam como professores afirmaram que não gostaram da experiência.

Grupo 2 - agrupado entre os escores positivos. Estes participantes apresentam valores de ER, QCR e IHS-Del-Prette significativamente maiores do que o primeiro grupo, pertencem aos cursos de Pedagogia e Ciências Biológicas, são do sexo masculino, apresentam maiores médias de idade, geralmente são casados e têm filhos. Grande parte desta amostra já trabalha, com elevadas médias de cargas horárias de trabalho e afirmaram que gostam de ser professores.

A diferenciação entre os dois grupos mostra que o grupo 1 apresentou a tendência a não gostar de ser professor e o grupo 2 gostar da docência, trabalhar com altas cargas horárias, e apesar de todas as dificuldades relacionadas à profissão, diz gostar do que faz. $\mathrm{O}$ professor precisa saber lidar com as adversidades que existem no seu cotidiano. Arroyo (2009) salienta que o trabalho docente não exige apenas um "dom" ou uma vocação para tal, requer que o professor invista no desenvolvimento de habilidades que lhe permitam saber enfrentar o dia a dia do ambiente escolar e assim vir a se tornar um professor competente.

Gatti (2010) realizou uma análise crítica dos dados sociodemográficos encontrados no Exame Nacional de Desempenho dos Estudantes (ENADE) de 2005, e constatou que para os alunos de licenciatura, exceto o curso de Pedagogia, escolher a docência pode ser como um "seguro desemprego" ou segunda opção caso não consigam exercer outra atividade. Quando o acadêmico escolhe a licenciatura com tal visão, tem maiores chances de não manter-se na profissão, respondendo provavelmente ao perfil traçado pelos componentes do Grupo 1.

O segundo agrupamento, caracterizado pelos que gostam de serem professores, envolve pessoas mais velhas, muitas delas casadas e com filhos, o que pode ser um indicativo de interesse pelo convívio com crianças e adolescentes, além de tratar-se de organizações familiares que podem impulsionar para a busca de uma segurança profissional, conforme apontado por Gatti (2010).

\section{Considerações finais}

Soares et. al. (2009) enfatizam que o professor, por ser um agente da educação, precisa ser socialmente competente, pois a forma como se comporta em sala de aula pode otimizar ou não a aprendizagem e o relacionamento entre ele e o educando. O papel de modelo de conduta desempenhado pelo professor é de suma importância especialmente na atualidade, quando se percebe que os conflitos são gerenciados na sociedade de forma impulsiva, levando a comportamentos lesivos para todos os envolvidos. Ter identificado predomínio de repertório apropriado de habilidades sociais e resiliência por parte dos acadêmicos que escolheram cursos envolvendo licenciatura, pode ser um indício produtivo 
no padrão de comportamento da sociedade. Se além da tendência identificada no estudo, de pessoas com maior índice de habilidades sociais buscarem a docência, os cursos tiverem instrumentos para investir no cultivo destas habilidades, evitando que o desgaste da rotina diária ou da exposição contínua a desafios prejudiquem o desempenho do docente, estar-se-á investindo na qualidade da educação. Investir no preparo do professor, para que consiga manter suas respostas habilidosas mesmo no passar dos anos de atuação profissional, pode vir a ser um importante desafio no sentido de prevenção, já que percebeu-se que as correlações negativas a) entre conversação e desenvoltura social e anos de atuação profissional; b) autoafirmação na expressão de sentimento positivo e carga horária de trabalho indicam fatores de risco que precisam ser analisados e receber atenção devida.

Não ter encontrado diferenças significativas entre os alunos dos diferentes cursos envolvendo licenciaturas fortalece a recomendação derivada da pesquisa realizada por Soares et. al. (2009) com professores de diferentes disciplinas. Na referida pesquisa os autores salientam que independente da sua área de conhecimento acadêmico, o professor necessita saber lidar de forma adequada com os seus alunos, para assim contribuir para um aprendizado efetivo e para a formação integral dos educandos.

Com a análise de redundância foi possível dividir a amostra em dois grupos distintos, sendo o grupo 1, no qual há profissionais mais jovens e não tão identificados com a docência como o grupo 2, que é caracterizado por inserir profissionais com uma idade mais avançada e casadas. Os resultados mostram o papel da maturidade para a escolha e desempenho profissional, pois o passar do tempo, assim como o aumento no número de responsabilidades ao longo da vida podem influenciar na forma de se encarar o trabalho e a profissão de professor (Gatti, 2010).

No ambiente escolar é comum encontrar conflitos como a violência, a indisciplina, o fracasso escolar, o desinteresse por parte dos discentes, a falta de infraestrutura escolar, entre outros. Porém raramente há, em cursos de graduação envolvendo as licenciaturas, uma disciplina formal que ensine habilidades sociais aos seus alunos, aspirantes a professores. A relação evidenciada entre habilidades sociais e resiliência pode indicar que o desenvolvimento de habilidades sociais pode levar a um aumento no nível de resiliência. Até o presente momento a aprendizagem de ambos os repertórios é assistemática, e por isso nem sempre garantida. Constatar a relação evidenciada no estudo pode contribuir para a oferta de trabalhos mais sistematizados visando ao desenvolvimento das habilidades sociais e resiliência.

\section{Referências}

Alberti, R. E. \& Emmons, M. L. (1978). Comportamento assertivo: um guia de autoexpressão. Trad. Jane Maria Corrêa. Belo Horizonte: Interlivros.

Arroyo, M. G. (2010). Ofício de mestre: imagens e auto-imagens. 12. ed. Petrópolis/RJ: Vozes.

Assis, S. G., Pesce, R. P.; \& Avanci, J. Q. (2006). Resiliência: enfatizando a proteção dos adolescentes. Porto Alegre: Artmed.

Barros, M. E. B. de \& Louzada, A. P. (2007). Dor-desprazer-trabalho docente: como desfazer essa tríade? Psicologia USP, 18(4), 13-34.

Benevides-Pereira, Ana Maria Teresa. (2002). Burnout: quando o trabalho ameaça o bem-estar do trabalhador. São Paulo: Casa do Psicólogo.

Camargo, D. de. (2004). As emoções e a escola. Curitiba-PR: Travessa dos editores. 
Del Prette, A. \& Del Prette, Z. A. P. (2006). Treinamento de habilidades sociais na escola: o método vivencial e a participação do professor. In: Bandeira, M.; Del Prette, Z. A. P. \& Del Prette, A. Estudos sobre habilidades sociais e relacionamento interpessoal. 1. ed. São Paulo: Casa do psicólogo, 143-160.

Del Prette, A. \& Del Prette, Z. A. P. (2011). Psicologia das relações interpessoais: vivências para o trabalho em grupo. 9. ed. Petrópolis-RJ: Vozes.

Del Prette, Z. A. P. \& Del Prette, A. (2007). Habilidades sociais e dificuldades de aprendizagem: teoria e pesquisa sob um enfoque multimodal. In: Del Prette, A. \& Del Prette, Z. A. P. Habilidades sociais, desenvolvimento $e$ aprendizagem. Campinas-SP: Editora Alínea, 167-206.

Del Prette, Z. A. P. \& Del Prette, A. (2008). Habilidades sociais e educação: pesquisa e atuação em psicologia escolar/educacional. In: Del Prette, Z. A. P. (Org.). Psicologia escolar e educacional, saúde e qualidade de vida: explorando fronteiras. 3. ed. Campinas-SP: Editora Alínea, 113- 141.

Del Prette, Z. A. P. \& Del Prette, A. (2001). Inventário de habilidades sociais (IHS-DEL-PRETTE): manual de aplicação, apuração e interpretação. São Paulo: Casa do Psicólogo.

Fajardo, I. N., Minayo, M. C. de S. \& Moreira, C. O. F. (2010). Educação escolar e resiliência: política de educação e a prática docente em meios adversos. Ensaio: avaliação e políticas públicas em educação, 18(69), 761-773.

Fajardo, I. N., Minayo, M. C. de S. \& Moreira, C. O. F. (2013). Resiliência e prática escolar: uma revisão crítica. Educação e sociedade, Campinas, 34, (122), 213-224.

Gatti, B. A. (2010). Formação de professores no Brasil: características e problemas. Educação e sociedade, Campinas, 31(113), 1355-1379.

Gomes, G. \& Soares, A. B. (2013). Inteligência, habilidades sociais e expectativas acadêmicos no desempenho de estudantes universitários. Psicologia: reflexão e crítica, 26(4), 780-789.

Gresham, F. M. (2009). Análise do comportamento aplicada às habilidades sociais. In: Del Prette, A. \& Del Prette, Z. Psicologia das habilidades sociais: diversidade teórica e suas implicações. Petrópolis, RJ: Vozes, 17-66.

Leite, C. R. \& Löhr, S. S. (2012). Conflitos professor-aluno: uma proposta de intervenção. Revista diálogo educacional, 12(36), 581-596.

Lopes, R. P. (2010). Da licenciatura à sala de aula: o processo de aprender a ensinar em tempos e espaços variados. Educar, Curitiba, 36, 163-179.

Loureiro, S. R. \& Sanches, S. H. B. (2006). Crianças com bom desempenho acadêmico: dificuldades comportamentais e eventos de vida. In: Bandeira, M.; 
Del Prette, Z. A. P. \& Del Prette, A. Estudos sobre habilidades sociais e relacionamento interpessoal. 1. ed. São Paulo: Casa do psicólogo, 69-88.

Masten, A. (2014). Global perspectives on resilience in children and youth. Child development, 85(1), 6-20.

Moser, A. M., Amorim, C. \& Angst, R. (2013). Burnout e resiliência em estudantes de Pedagogia de Curitiba-PR. PsicoFae, 2(2), 49-58.

Pesce, R. P., Assis, S. G., Avanci, J. Q., Santos, N., Malaquias, J. V. \& Carvalhaes, R. (2005). Adaptação transcultural, confiabilidade e validade da escala de resiliência. Cadernos de Saúde Pública, 21(2), 436-448.

Poletto, M. \& Koller, S. H. (2008). Contextos ecológicos: promotores de resiliência, fatores de risco e de proteção. Estudos de Psicologia, Campinas, 25(3), 405-416.

Pretsch, J., Flunger, B. \& Schmitt, M. (2012). Resilience predicts well-being in teachers, but not in non-teaching employees. Social psychology education, 15, 321-336.

Richardson, J. (2013). Seeing an invisible world: let's make sure that cultural and interpersonal awareness are on the menu in our schools and throughout our nation. Phi delta kappan, 94(6), 4.

Rutter, M. (2007). Resilience, competence and coping. Child abuse \& neglect, 31(3), 205-209.

Soares, A. B. \& Mello, T. V. dos S. (2010). Habilidades sociais entre professores e não professores. Revista brasileira de terapias cognitivas, 5(2), $15-27$.

Soares, A. B., Naiff, L. A. M.; Fonseca, L. B. da; Cardozo, A. \& Baldez, M. de O. (2009). Estudo comparativo de habilidades sociais e variáveis sociodemográficas de professores. Psicologia: teoria e prática, 11(1), 35-49.

Vedovato, T. G. \& Monteiro, M. I. (2008). Perfil sociodemográfico e condições de saúde e trabalho dos professores de nove escolas estaduais paulistas. Revista da Escola de Enfermagem da USP, 42(2), 290-29. 